\title{
IMPACT OF USING STONE POWDER AND MINERAL ADMIXTURES IN HIGH STRENGTH CONCRETE
}

\author{
Syed Afzal Basha', Dr. B. Jayarami Reddy², Dr. C. Sashidhar ${ }^{3}$ \\ ${ }^{1}$ Research Scholar, JNT University, Anantapur, A.P.[syedafzal74@gmail.com] \\ ${ }^{2}$ Professor \& HOD, YSR Engineering College of YVU, Prodattur. [bjreddyyvuce@gmail.com] \\ ${ }^{3}$ Director of Evaluation, JNT University, Anantapur, A.P.[sashigunt@gmail.com]
}

\begin{abstract}
In present era, high-strength concrete is progressively utilized in modern concrete technology and particularly in the construction of elevated structures. This examination has been directed to explore the properties of high-strength concrete that was delivered by using stone powder (SP) as an option of extent on sand after being processed. The aim of the research is to study the effect of replacement of sand with stone powder and substitution of cement with mineral admixtures (GGBS \& Zeolite) on the mechanical properties of high strength concrete. The test results showed clear improvement in compression and split tensile nature of concrete by using stone powder and mineral admixtures together in concrete. The increment in the magnitude of compressive strength and split tensile strength are comparable with conventional concrete.
\end{abstract}

Key Words: Stone Powder, Mineral Admixtures, High strength concrete, Mechanical properties

\section{INTRODUCTION}

Considering the volume, concrete is the first mostly used building material in the world. The definition of high strength changes over the years as concrete strength used in the field increases. High strength concrete is a kind of superior performance concrete by and large with a predetermined compressive quality of $40 \mathrm{MPa}$ or more. Over the most recent couple of decades, extensive exploration exertion has been spent on the use of industrial by product (fly ash, blast furnace slag, silica fume, etc.) and characteristic assets (lime stone, pozzolans, etc.) as substitution of Portland cement. Supplementary cementitious materials can be utilized for improved concrete performance in its fresh and hardened state. They are basically used for improved workability, durability and strength. These materials permit the concrete producer to design and modify the concrete mixture to suit the ideal application [1]. Many researches examine the possibility of using stone powder, limestone powder as partial replacement of sand and partial replacement of cement. The test outcomes demonstrate that granite powder of marginal amount as fractional sand substitution has advantageous impact on the mechanical properties such as compressive strength, split tensile strength, modulus of elasticity [2]. The point of this examination is to contemplate the impact of stone powder utilized as mostly substitution of sand on significant mechanical properties of hardened concrete. The goal of this paper is to provide insight into the challenges of utilizing SCMs in order to better predict their performance. The development of alternative SCMs for concrete will help ensure availability of high-quality concrete with minimized environmental impact into the future.

\section{SUPPLEMENTARY CEMENTITIOUS MATERIALS}

Supplementary cementing materials (SCMs) add to the properties of hardened concrete through water driven or pozzolanic activity. Commonplace models are fly ash, ground granulated blast-furnace slag, rice husk ash and silica-fume. There are various advantages of incorporating supplementary cementitious materials into blend structure. Not only will SCMs allow cement contents to be reduced, they will also improve both the fresh and hydrated properties and performance of concrete. 
Website: ijetms.in Issue:5, Volume No.4, September-2020 DOI: DOI: 10.46647/ijetms.2020.v04i05.015

A pozzolan is a siliceous or siliceous and aluminous material that in itself has almost no cementitious worth however will, in finely divided form and in the presence of moisture, chemically respond with calcium hydroxide at conventional temperatures to form compounds having cementitious properties. SCMs are used to substitute either Portland cement clinker in creation of composite cements or cement in the production of concrete. The utilization of SCMs is broad in the concrete industry due to the financial and performance benefits they offer. More of late, SCMs have been accepting expanding consideration for the role they play in reducing the carbon footprint of concrete, since the energy use and $\mathrm{CO} 2$ emissions from Portland cement clinker manufacturing significantly outweigh those of other concrete components, and SCMs have a smaller environmental impact than Portland cement clinker [3]. They are made out of comparable materials and respond with the products of hydrating cement to create extra cementitious folio. Pozzolanic material can be utilized to alter and improve plastic and solidified properties of concrete [4]. Various types of supplementary cementing materials:

Silica fume: It is a highly reactive pozzolanic material and is a byproduct from the manufacture of silicon or Ferro-silicon metal. It is collected from the flue gases from electrical arc furnaces. Silica fume is an extremely fine powder, with particles about 100 times smaller than an average cement grain. Silica fume is available as a densified powder or in a water-slurry form.

Fly ash: It is a byproduct of coal-fired furnaces at power generation facilities and is the noncombustible particulates removed from the flue gases.

Ground blast furnace slag: It is a non-metallic manufactured byproduct from a blast furnace when iron ore is reduced to pig iron. The liquid slag is rapidly cooled to form granules, which are then ground to fineness similar to Portland cement. Ground granulated blast furnace slag (GGBFS) used as a cementitious material.

Rice husk ash: Rise husk ash (RHA) is a natural byproduct from the processing of paddy rise. The husks, which are approximately 50 percent cellulose, 30 percent lignin and 20 percent silica, are incinerated by controlled combustion leaving behind an ash that predominantly consists of amorphous silica.

Metakaolin: It is an alumino-silicate mineral product, produced in volumes exceeding several million tons per annum worldwide by thermal transformation of kaolinite, which is mined in many parts of the world. Calcination of kaolinite at between $550-750^{\circ} \mathrm{C}$ gets dried out and amorphizes its crystalline structure, bringing about a material which needs long-extend orders [5]. The substance and auxiliary strain incited by warm handling bring about an alumino-silicate material which is adequately receptive to give successful pozzolanic movement [6]. It should be noted that the calcination temperature should be carefully controlled to avoid formation of inert phases such as mullite.

\section{EXPERIMENTAL PROGRAM}

\section{A. Materials}

Cement: Ordinary Portland cement (OPC) conforming to Grade 53, is used in the proposed work. Cement used conforms to IS: 8812-1989 \& IS: 12269-1987 respectively.

Stone Powder: Among the numerous materials researched, quarry dust has all the earmarks of being the most reasonable on the grounds that it is accessible in huge amounts in many pieces of the world [7]. The properties of concrete (Compressive and split tensile quality) made with halfway or full supplanting with stone dust are equivalent to natural sand results [8]. 


\section{International Journal of Engineering Technology and Management Sciences[IJETIS]}

Website: ijetms.in Issue:5, Volume No.4, September-2020 DOI: DOI: 10.46647/ijetms.2020.v04i05.015

Fine aggregate: It is the aggregate most of which passes through a $4.75 \mathrm{~mm}$ IS sieve and contains only that much coarser material as is permitted by specifications. Sand is generally considered to have a lower size limit of about $0.07 \mathrm{~mm}$. The sand used in this investigation is ordinary river sand obtained from the banks of Tungabhadra River. The sand is free from clayey matter, silt and organic impurities etc. The sands are commonly isolated into various zones as indicated by the rates passing the IS: 600 micron strainer. IS: 383-1970 groups the sand into four zones, I, II, III and IV with the goal that the scope of rate passing the 600 micron sifter in each zone doesn't cover. The sand utilized for the current examination falls in zone-II according to as far as possible.

Coarse aggregate: The aggregates most of which are held on $4.75 \mathrm{~mm}$ IS sifter and contain only that much of fine material as permitted by the specifications are termed as coarse aggregates. 20 $\mathrm{mm}$ nominal size of coarse aggregate was utilized in the experimentation. A graded aggregate of nominal size $20 \mathrm{~mm}$ means an aggregate most of which passes the $20 \mathrm{~mm}$ IS sifter. Since the aggregates are formed due to natural disintegration of rocks or by the artificial crushing of rock or gravel, they derive many of the properties from the parent rocks. The physical properties have been determined in accordance with the guidelines mentioned in IS: 2386-1963.The coarse aggregate was free from clayey matter, silt and organic impurities etc. The specific gravity of the coarse aggregate was 2.71 and fineness modulus was 3.79 .

Water: Potable water free from suspended solids and organic materials was used. The water utilized for both blending and curing of concrete was free from polluting influences, damaging measures of acids, antacids, oils, salts, natural issue or different substances that might be malicious to cement or steel. The presence of chlorides and sulfates are injurious to reinforcing bars as they may be corroded. The general requirements of water for blending and curing of concrete shall be as per guidelines of IS 456- 2000.

Zeolite: Natural zeolites are alumino-silicates of alkaline and alkaline earth cations such as potassium $(\mathrm{K})$, calcium $(\mathrm{Ca})$, and sodium $(\mathrm{Na})$. They form the largest and most varied mineral group of the earth's crust. The main features of zeolites are an open structure and ability to accommodate water and cations within the structure and give them up without changing its structure significantly. Structurally they are considered hydrated aluminum tecto-silicates where aluminum is replacing silicon $(\mathrm{Si})$ at the center of the structural tetrahedrons, with alkaline and alkaline earth cations forming open structures [9]. In particular, zeolite application in cementitious materials such as mortar and concrete adds to upgrading the mechanical properties of these materials also to perceptible increment obstruction chloride particle dispersion, their freeze-thaw resistance, and overall permeability [10]. It likewise expands their sulfate resistance, enabling them to be used in aggressive conditions, such as special foundations or infusion mortars.

\section{Ground Granulated Blast furnace Slag (GGBS):}

It is a result from the impact heaters used to make iron. These work at a temperature of around 1500 degrees centigrade and are taken care of with a painstakingly controlled blend of iron mineral, coke and limestone. The iron mineral is diminished to press and the rest of the materials from a slag that coasts on head of the iron. This slag is intermittently tapped off as a liquid fluid and on the off chance that it is to be utilized for the production of GGBS it must be quickly extinguished in huge volumes of water. The extinguishing improves the cementitious properties and produces granules like coarse sand. This granulated slag is then dried and ground to a fine powder. 


\section{International Journal of Engineering Technology and Management Sciences[IJETMS]}

Website: ijetms.in Issue:5, Volume No.4, September-2020 DOI: DOI: 10.46647/ijetms.2020.v04i05.015

\section{B. Mix Proportions}

Four distinctive mix proportions were prepared. The first blend was prepared from $100 \%$ stream sand and cement content to deliver conventional concrete. The second mix was prepared using $50 \%$ stone powder, $50 \%$ sand and $100 \%$ cement. The third mix was produced using $50 \%$ stone powder + $50 \%$ natural sand $+40 \%$ GGBS $+60 \%$ cement The fourth mix was produced using $50 \%$ stone powder $+50 \%$ natural sand $+40 \%$ GGBS $+10 \%$ zeolite + $50 \%$ cement The water cement ratio for all the blends was fixed at 0.3 , by weight.

Table- I: Mix Proportions for M60 grade of concrete

\begin{tabular}{|l|l|l|}
\hline Cement & $449 \mathrm{~kg} / \mathrm{m}^{3}$ & 1 \\
\hline SCM & $112 \mathrm{~kg} / \mathrm{m}^{3}$ & 0.249 \\
\hline Fine Aggregate & $664.52 \mathrm{~kg} / \mathrm{m}^{3}$ & 1.48 \\
\hline Coarse & $20 \mathrm{~mm}-808.28$ & 2.21 \\
Aggregate & $\mathrm{kg} / \mathrm{m}^{3}$ & \\
& $12.5 \mathrm{~mm}-202.1$ & \\
& $\mathrm{~kg} / \mathrm{m}^{3}$ & \\
\hline Water & $153 \mathrm{~kg} / \mathrm{m}^{3}$ & 0.3 \\
\hline SP & $62 \mathrm{~kg} / \mathrm{m}^{3}$ & 0.138 \\
\hline
\end{tabular}

\section{Methods}

This exploration was led in the laboratory to decide the conduct of the concrete in terms of mechanical quality and durability properties. The extent of work covers the mechanical and physical properties with $50 \%$ quarry dust as fine aggregate and fractional substitution of cement with mineral admixtures like GGBS and Zeolite. The mechanical properties of solidified concrete were attempted through the compressive strength test with cubes $150 \mathrm{~mm} \times$ $150 \mathrm{~mm} \times 150 \mathrm{~mm}$ shape. The cube samples were tested at the ages of 7 and 28 days after the wet curing process at the restoring tank in agreement to strategies of IS 9013: (1978). The split tensile strength was carried out on the standard test cylinder of concrete specimen of $150 \mathrm{~mm}$ diameter and $300 \mathrm{~mm}$ height. This test was carried out as per IS: 5816-1970.

The fresh properties of the green concrete are resolved through the slump test for the best workability, it is done as per IS $1199-1959$, for sampling at site and at the lab. The chemical admixture utilized in this examination was SP 430 Conplast super plasticizer. It is required because of the lower use of water to deliver high strength GGBS concrete that would influence the workability of new concrete. Modification was being made to guarantee the best usefulness acquired with best flow slump without endangering the concrete quality. It is utilized at a measurement rate, $2 \%$ of the cement by weight. The cementitious materials were mixed for 4 to 5 minutes in a mechanical blender at a speed of $80 \mathrm{rpm}$ to ensure homogeneous blending. Water was then included and mixed with all the supplementary cementitious materials for 5 minutes, followed by 2 minutes resting period to scratch off any unmixed powders from the paddle sides of the blender and including them into the mixing bowl. The mixing was continued for an additional time of 5 minutes before placing the fresh concrete in 3D shaped molds. After complete mixing, the fresh paste was placed into $150 \mathrm{~mm}$ cube moulds and vibrated for 1 minute to expel air bubbles. Immediately after casting the moulds were covered with a polyethylene sheet to dodge any evaporating of water from the surface of the samples.

Table- II: Compression \& Split Tensile Test Results

\begin{tabular}{|c|c|c|c|c|c|}
\hline Mix & Mixture & \multicolumn{2}{|c|}{$\begin{array}{c}\text { Compressive } \\
\text { Strength } \\
\left(\mathbf{N} / \mathbf{m m}^{2}\right)\end{array}$} & \multicolumn{2}{|c|}{$\begin{array}{c}\text { Split Tensile } \\
\text { Strength } \\
\left(\mathbf{N} / \mathbf{m m}^{2}\right)\end{array}$} \\
\cline { 3 - 6 } & & $\mathbf{7}$ & $\mathbf{2 8}$ & $\mathbf{7}$ & $\mathbf{2 8}$ \\
\hline M-1 & $100 \%$ natural river & 39.12 & 58.13 & 2.98 & 5.79 \\
\hline
\end{tabular}




\section{International Journal of Engineering Technology and Management Sciences[IJETVIS]}

Website: ijetms.in Issue:5, Volume No.4, September-2020 DOI: DOI: 10.46647/ijetms.2020.v04i05.015

\begin{tabular}{|c|c|c|c|c|c|}
\hline & sand $+100 \%$ cement & & & & \\
\hline M-2 & $\begin{array}{c}50 \% \text { stone powder }+ \\
50 \% \text { natural sand }+ \\
100 \% \text { cement }\end{array}$ & 38.46 & 57.52 & 2.75 & 5.53 \\
\hline M-3 & $\begin{array}{l}50 \% \text { stone powder }+ \\
50 \% \text { natural sand }+ \\
40 \% \text { GGBS }+60 \% \\
\text { cement }\end{array}$ & 38.58 & 61.21 & 3.05 & 6.31 \\
\hline M-4 & $\begin{array}{c}50 \% \text { stone powder }+ \\
50 \% \text { natural sand }+ \\
40 \% \text { GGBS }+10 \% \\
\text { zeolite }+50 \% \text { cement }\end{array}$ & 37.59 & 59.61 & 3.11 & 6.41 \\
\hline
\end{tabular}

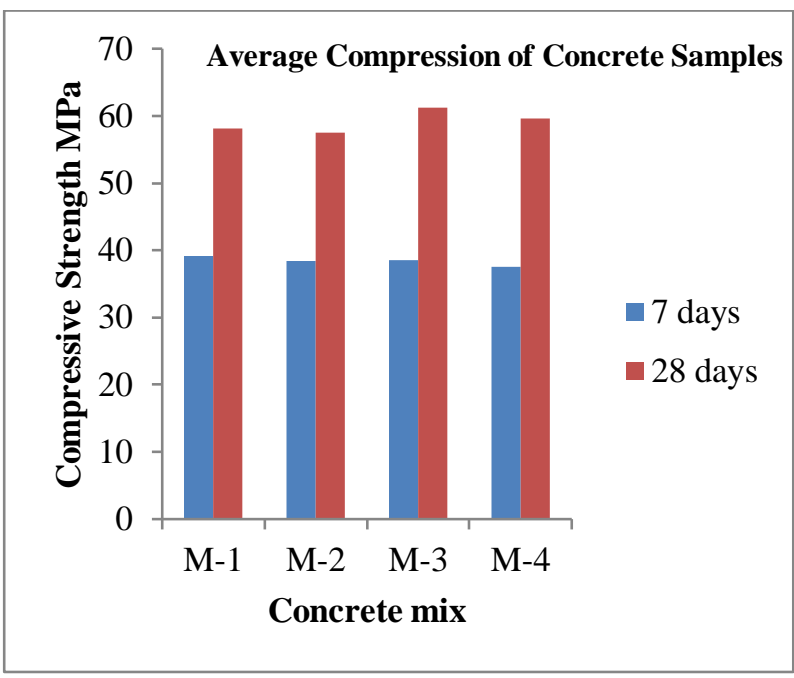

Fig. 1 Variation of Compressive Quality of cube samples at Different Ages

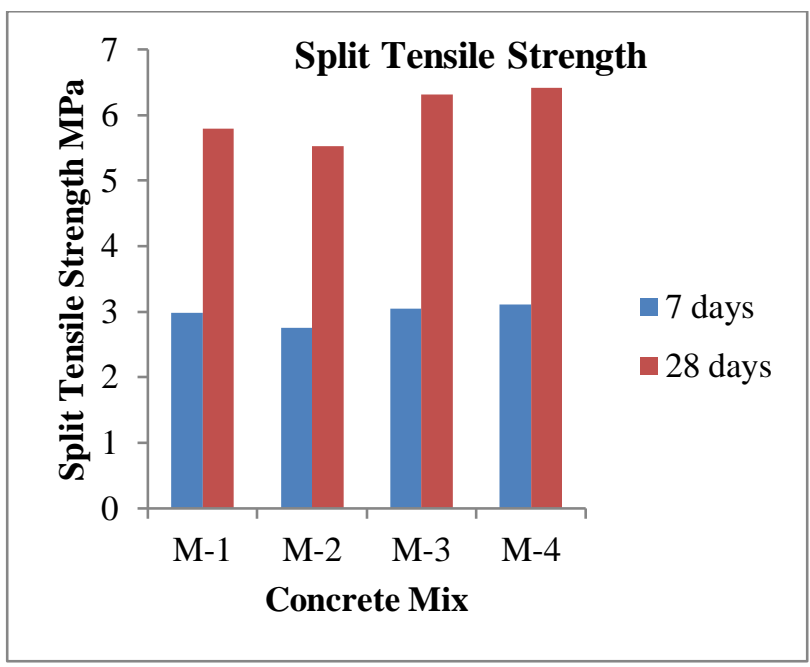

Fig. 2 Variation of Split Tensile Strength at Different Ages

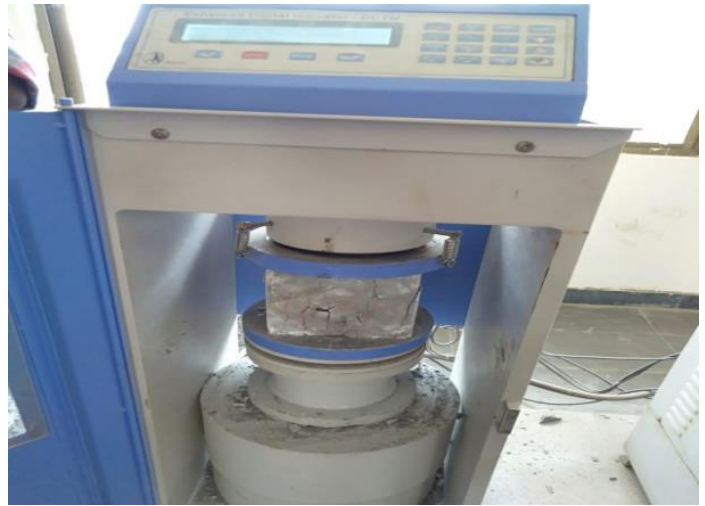

Fig.3 Testing of cube specimen

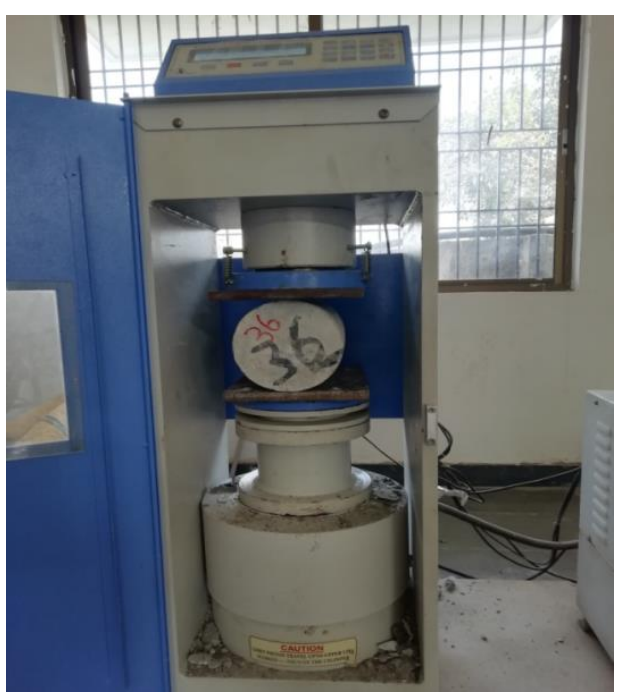

Fig.4 Testing of cylindrical specimen

\section{RESULTS AND DISCUSSION}

The compression test results of M60 grade concrete cube specimens at 7 and 28 days typical curing, with 0 and $50 \%$ supplanting of fine sand with stone residue. A slow increment in compression quality was seen up to half substitution. Maintaining halfway substitution of stone powder, when cement is being replaced with $40 \%$ GGBS, the compressive strength of 61.21 $\mathrm{MPa}$ was recorded. Later on, when cement is supplanted with $40 \%$ GGBS and $10 \%$ zeolite, a compressive strength of $59.61 \mathrm{MPa}$ was noticed. The option of stone residue diminished the workability of concrete and henceforth the super 


\section{International Journal of Engineering Technology and Management Sciences[IJETVIS]}

Website: ijetms.in Issue:5, Volume No.4, September-2020 DOI: DOI: 10.46647/ijetms.2020.v04i05.015

plasticizer (of 1\%) was included, and minimal increments in compression were watched. Compression test results acquired were equivalent with the ordinary cement concrete. The same trend was observed with respect to split tensile strength of concrete samples.

\section{CONCLUSIONS}

$>$ High strength concrete can be produced by using stone powder as partial replacement of sand

$>$ Stone powder and each mineral such as blast furnace slag \& zeolite can play a part to improve the performance of concrete. Since each mineral has one or two useful characteristics in binder blends, incorporations of two or three supplementary cementitious materials have been explored by different experts, and different properties such as, compressive strength, tensile strength have been studied

$>$ At 28 days, the compressive strength results of samples containing stone powder are of acceptable range

$>$ The most suitable percentage of stone powder as partial replacement of sand was $50 \%$, which gave highest activity index

$>$ Splitting and compressive strength increased; therefore the use of mineral admixture with combination of stone powder can be recommended

$>$ The above conclusion gives clear picture that there is no damage in using quarry dust as a substitute for characteristic stream sand in concrete blends if unadulterated by soil and other polluting influences

$>$ Still, more tests should be run in order to prove the quality of concrete containing high volume supplementary cementitious material. Brittle behavior, crack formation, shrinkage, corrosion time initiation, passivity, carbon dioxide absorption, etc. are still question marks in the multi blended cement concrete field

\section{REFERENCES}

[1] Scrivener, Karen L (2008). Innovation in use and research on cementitious material. Cement and Concrete Research , pp 128-136.

[2] T, Felixkala and P. Partheeban (2010). Granite powder concrete, Indian Journal of science and Technology . vo1.3. No.3 march.

[3] P. Van den Heede and N. De Belie, Cem. Concr. Comp. 34, 431 (2012).

[4] Aitcin P.-C., and Neville A.M(1993). HighPerformance Concrete Demystified. Concrete International15, pp 21-26.

[5] G.W. Brindley and M. Nakahira, J.Am. Ceram. Soc. 42 (7), 311

[6] B.B. Sabir, S. Wild and J. Bai, Cem. Concr. Comp. 23(6), 441

[7] C.K. Kankam et al, "Stress-strain characteristics of concrete containing quarry rock dust as partial replacement of sand" Case Studies in Construction Materials 7 (2017) 6672 www.elsevier.com/locate/csc

[8] S Mundra et al, "Crushed rock sand - An economical and ecological alternative to natural sand to optimize concrete mix" Perspectives in Science 2016(8), 345-347

[9] M. Najimi, J. Sobhani, B. Ahmadi, M. Shekarchi, "An experimental study on durability properties of concrete containing zeolite as a highly reactive natural pozzolan" Construction and Building Materials, 35, 2012, pp. 1023-1033

[10] B. Uzal, L. Turanli, "Blended cements containing high volume of natural zeolites: Properties, hydration and paste microstructure" Cement and Concrete Composites, vol. 34, January 2012, pp. 101-1 